\title{
Foreword of the editor
}

\author{
Editor in Chief: Gábor L. Kovács, M.D., Ph.D., DSc
}

Professor Edgard Delvin (Canada) was asked to be the guest-editor of the special issue on "Recent advances in pediatric laboratory medicine". After obtaining a PhD degree in biochemistry at the University of Montreal, Dr. Delvin pursued his post-doctoral training in Biochemical Genetics at the Montreal Children's Hospital (McGill University). In 1973 he joined the Shriners Hospital for Children, affiliated to McGill University, where he became senior investigator and Associate Director of the Genetics Unit as well as being Associate Professor in the Department of Experimental Medicine.

In 1992, the University of Montreal recruited him to chair the Department of Clinical Biochemistry at the University-affiliated SainteJustine Hospital. He also was appointed as full Professor of Biochemistry in the Department of Biochemistry of the Faculty of Medicine. After his retirement in 2012 he acted as consultant for the Montreal Children's Hospital, affiliated with McGill University until 2014.

He has served on the Paediatric Endocrinology Teaching Program of the University of Montreal until August 2012. After being Editor-in-Chief of the Journal Clinical Biochemistry from 2006 to 2012, he now is the Special Issues Editor.

In terms of international activities, he has been Editor-in-chief of the IFCC eNewsletter from 2006 till 2012 and now chairs the IFCC Committee for Public Relations (C-PR) as well as being Vice-Chair of the CPD-EC.

He has authored or co-authored 245 articles, published in internationally recognized journals, and 9 book chapters.

In 2003 he received the research Excellence Award from the Canadian Society of Clinical Chemists, and is a Member of the French Académie Nationale de Médecine. 